\title{
Impaired Attention in the 3xTgAD Mouse Model of Alzheimer's Disease: Rescue by Donepezil (Aricept)
}

\author{
Carola Romberg, ${ }^{1}$ Mark P. Mattson, ${ }^{3}$ Mohamed R. Mughal, ${ }^{3}$ Timothy J. Bussey, ${ }^{1,2}$ and Lisa M. Saksida ${ }^{1,2}$ \\ ${ }^{1}$ Department of Experimental Psychology and ${ }^{2}$ Wellcome Trust and Medical Research Council Behavioural and Clinical Neuroscience Institute, \\ University of Cambridge, Cambridge CB2 3EB, United Kingdom, and ${ }^{3}$ National Institute on Aging Intramural Research Program, Baltimore, \\ Maryland 21224-6825
}

Several mouse models of Alzheimer's disease (AD) with abundant $\beta$-amyloid and/or aberrantly phosphorylated tau develop memory impairments. However, multiple non-mnemonic cognitive domains such as attention and executive control are also compromised early in AD individuals. Currently, it is unclear whether mutations in the $\beta$-amyloid precursor protein (APP) and tau are sufficient to cause similar, AD-like attention deficits in mouse models of the disease. To address this question, we tested 3xTgAD mice (which express APPswe, PS1M146V, and tauP301L mutations) and wild-type control mice on a newly developed touchscreen-based 5-choice serial reaction time test of attention and response control. The 3xTgAD mice attended less accurately to short, spatially unpredictable stimuli when the attentional demand of the task was high, and also showed a general tendency to make more perseverative responses than wild-type mice. The attentional impairment of 3xTgAD mice was comparable to that of $\mathrm{AD}$ patients in two aspects: first, although 3xTgAD mice initially responded as accurately as wild-type mice, they subsequently failed to sustain their attention over the duration of the task; second, the ability to sustain attention was enhanced by the cholinesterase inhibitor donepezil (Aricept). These findings demonstrate that familial AD mutations not only affect memory, but also cause significant impairments in attention, a cognitive domain supported by the prefrontal cortex and its afferents. Because attention deficits are likely to affect memory encoding and other cognitive abilities, our findings have important consequences for the assessment of disease mechanisms and therapeutics in animal models of AD.

\section{Introduction}

Alzheimer's disease $(\mathrm{AD})$ is a progressive, neurodegenerative disease characterized by a gradual but profound decline in cognitive abilities and the appearance of $\beta$-amyloid and tau aggregates (plaques and tangles) in the brain. Because the loss of episodic memory is the most common symptom lamented by affected patients (Huff et al., 1987a,b; Welsh et al., 1992; Artero and Ritchie, 2003), the disease is often regarded simply as a memory disorder. However, multiple cognitive domains are compromised in the majority of $\mathrm{AD}$ individuals: deficits of sustained attention (vigilance) and executive functioning (inhibitory control) occur early in the disease and can precede language and spatial impairments (Sahakian and Coull, 1993; Sahakian et al., 1993; Lawrence and Sahakian, 1995; Reid et al., 1996; Perry et al., 2000; Baddeley et al., 2001; Foldi et al., 2005b; Levinoff et al., 2005; Bentley at al., 2008). Thus, understanding the nature of attention deficits in early $\mathrm{AD}$ may provide insights into the mechanisms that dissociate $\mathrm{AD}$ from normal aging.

Mutations in genes encoding $\beta$-amyloid precursor protein (APP) or presenilin 1 lead to inherited, early-onset forms of AD

Received Sept. 27, 2010; revised Dec. 9, 2010; accepted Jan. 6, 2011.

This research was supported by the Alzheimer's Research Trust, the Wellcome Trust, the Medical Research Council, and the Intramural Research Program of the National Institute on Aging, National Institutes of Health.

Correspondence should be addressed to Carola Romberg at the above address. E-mail: carola.romberg@ gmail.com.

DOI:10.1523/JNEUROSCI.5242-10.2011

Copyright $\odot 2011$ the authors $\quad 0270-6474 / 11 / 313500-08 \$ 15.00 / 0$
(Haass, 1997; Selkoe, 1998), and mutations in the microtubuleassociated protein tau cause some cases of frontotemporal lobe dementia (Dermaut et al., 2005). Transgenic mice overexpressing these altered human genes develop age-dependent learning and memory deficits, thus mimicking important behavioral aspects of the disease (Götz and Ittner, 2008). However, it is unclear whether such mouse models also develop attentional impairments similar to those found in early AD patients.

A comprehensive mouse model with plaques, tangle-like tauopathy, and memory impairments is the $3 \mathrm{xTgAD}$ mouse carrying human $A P P_{\text {swe }}$ and $t a u_{\mathrm{P} 301 \mathrm{~L}}$ transgenes as well as a $P S 1_{\mathrm{M} 146 \mathrm{~V}}$ knock-in (Oddo et al., 2003a). Here, we tested 3xTgAD mice on a computer-automated touchscreen version of the 5-Choice Serial Reaction Time Task (5-CSRTT) (Carli et al., 1983; Robbins, 2002), a rodent task nearly identical to touchscreen-based tasks used to study sustained attention in AD patients (Sahakian and Coull, 1993; Sahakian et al., 1993). The 5-CSRTT, formerly run in a 5- or 9-hole box, has been extensively used to assess sustained spatial attention divided among a number of locations across a large number of trials in rats (Muir et al., 1994; Mirza and Stolerman, 2000) and, recently, mice (Humby et al., 1999; de Bruin et al., 2006; Patel et al., 2006; Lambourne et al., 2007; Pattij et al., 2007).

Attention is strongly modulated by cholinergic input from the basal forebrain (Bentley et al., 2003), and cholinergic manipulations have a large effect on the 5-CSRTT (Muir et al., 1992; Jones and Higgins, 1995; Blondel et al., 2000; Mirza and Stolerman, 
a

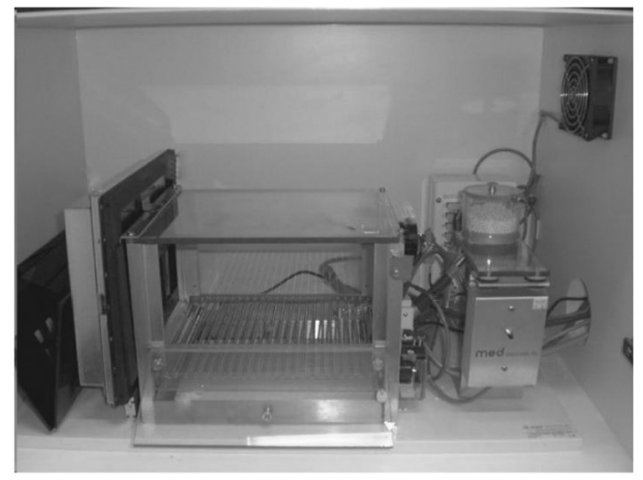

b

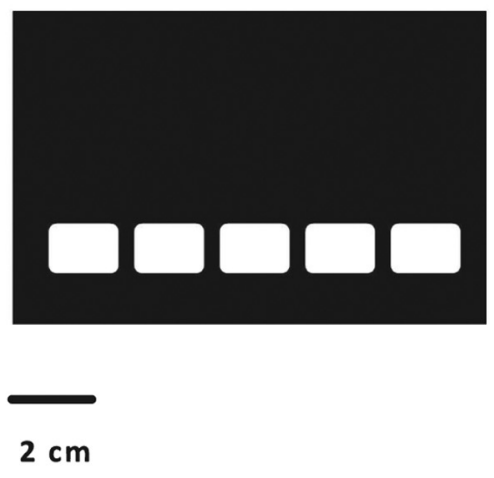

Figure 1. Testing apparatus. $\boldsymbol{a}$, Photograph of the adapted standard mouse operant chamber with the touch-sensitive monitor on the front side of the chamber, and pellet receptacle (with light and nosepoke detector), speaker and houselight at the back of the chamber. $\boldsymbol{b}$, The touchscreen was covered by a black mask with 5 response holes to focus responding.

2000; McGaughy et al., 2002; Dalley et al., 2004). As cholinergic neurons are particularly vulnerable to $\mathrm{AD}$-related degeneration (Davies and Maloney, 1976; Whitehouse et al., 1982), and the anticholinesterase donepezil improves attention both in $\mathrm{AD}$ patients (Rockwood et al., 2004; Foldi et al., 2005a) and in rats with basal forebrain lesions (Balducci et al., 2003), we also assessed whether donepezil affected 5-CSRTT performance of 3xTgAD mice.

\section{Materials and Methods}

Animals. 3xTgAD mice were bred at the National Institute on Aging in Baltimore, Maryland and shipped to the United Kingdom for behavioral testing. The original line of 3xTgAD mice was generated as described previously (Oddo et al., 2003a). Briefly, two transgene constructs encoding human APP $\left(A P P_{\text {swe }}\right)$ and tau $(P 301 L)$ were coinjected into singlecell embryos harvested from presenilin-1 (M146V) knock-in mice, which were reimplanted into foster mothers. Resulting offspring were genotyped to identify the $3 \mathrm{xTgAD}$ mice, which were backcrossed onto $\mathrm{C} 57 \mathrm{BL} / 6$ mice for 10 generations. The 3xTgAD mice used in the present study, eight 3xTgAD and eight C57BL/6J wild-type (wt) controls, were 9 months old at the onset of behavioral testing. At this age $3 \times$ TgAD mice exhibit few or no extracellular $A \beta$ deposits and relatively low levels of hyperphosphorylated tau, but do exhibit impaired hippocampal synaptic plasticity and a learning and memory deficit (Nelson et al., 2007; HirataFukae et al., 2008; Wang et al., 2009).

Mice were housed in groups of 2 or 3 , in a room with a $12 \mathrm{~h}$ light/dark cycle (lights off at 7:00 P.M.). All behavioral testing was conducted during the light phase of the cycle. Mice were maintained on a restricted diet and kept at $85 \%$ of free-feeding body weight during behavioral testing. Water was available ad libitum throughout the experiment. All experimentation was conducted in accordance with the United Kingdom Animals (Scientific Procedures) Act (1986).

Apparatus. Testing was conducted in a touchscreen-based automated operant system for mice (Fig. 1a). The apparatus consisted of a standard modular testing chamber housed within a sound- and light-attenuating box $(40 \times 34 \times 42 \mathrm{~cm}$, Med Associates Inc.). The inner operant chamber consisted of a metal frame, clear Perspex walls, and a stainless steel grid floor. The box was fitted with a fan (for ventilation and masking of extraneous noise) and a pellet receptacle (magazine), which was illuminated by a $3 \mathrm{~W}$ light bulb and fitted with a photocell head entry detector attached to a $14 \mathrm{mg}$ pellet dispenser (situated outside of the box). A $3 \mathrm{~W}$ houselight and a tone generator (Med Associates) were fitted to the back wall of the chamber. At the end of the box, opposite the magazine, was a flat-screen monitor equipped with an infrared touchscreen $(16 \mathrm{~cm}$ high and $21.20 \mathrm{~cm}$ wide; Craft Data Ltd) controlled by ELO touchscreen software (ELO TouchSystems Inc.). A black Perspex "mask" with 5 response windows was placed over the screen, to reduce unintended responding by tail or other body parts (Fig. 1b). Stimulus delivery/detection and operant box input/outputs were controlled with custom written software (MouseCat, L. M. Saksida, University of Cambridge, Cambridge, UK) written in Visual Basic 6 (Microsoft).

Shaping. Mice were trained to operate the touchscreen by a series of shaping procedures. For the first $2 \mathrm{~d}$, animals were habituated to the operant box environment for $15 \mathrm{~min}$ a day. During this phase, the house light was on, the touchscreen remained inactive and the magazine was filled with 10 reward pellets. In the following Pavlovian phase ( $1 \mathrm{~d}, 30$ trials), a single stimulus (a white square box, $2 \mathrm{~cm} \times 2 \mathrm{~cm}$ ), was randomly displayed in 1 of the 5 response windows. After $30 \mathrm{~s}$, the stimulus disappeared, coinciding with a tone, the onset of the magazine light, and the delivery of a reward pellet. When the animal collected the reward, the magazine light extinguished and the next trial commenced with the delivery of a new stimulus. A response to the stimulus on the screen was rewarded with the delivery of a tone and three extra pellets. At the next stage, the stimulus remained on the screen until the mouse touched the stimulus, which was rewarded with a single pellet, tone, and illumination of the magazine light. The collection of the reward pellet triggered a 20 s intertrial interval (ITI) (houselight on, no stimulus, magazine inactive) after which the next trial commenced, and a new stimulus was presented in 1 of the 5 windows. Training continued until the animal completed 30 trials within $15 \mathrm{~min}$ for two consecutive days. The final stage of shaping introduced the initiation procedure. At the onset of each trial, the magazine was illuminated, and the animal was required to initiate the stimulus delivery by a nosepoke into the magazine. Successful initiation was indicated by the extinction of the magazine light and the subsequent display of a stimulus. After touching the stimulus and collecting the reward, a 20 s ITI was implemented (houselight on, no stimulus), before the onset of the magazine light indicated the beginning of the new trial. Once animals readily initiated trials and completed 30 trials within 30 min for 2 consecutive days, they started 5-CSRTT training.

5-CSRTT training. The overall 5-CSRTT task procedure was similar to those previously described with 5 or 9 hole operant boxes (Carli et al., 1983; Lambourne et al., 2007). For the computer touchscreen version of the 5-CSRTT, mice were trained to respond to brief flashes of light pseudorandomly displayed in one of the five spatial locations on the touchscreen. Mice were tested 5-6 d a week, 50 trials a day (or up to $1 \mathrm{~h}$ ). Each trial commenced with the illumination of the magazine light. In contrast to the last stage of shaping, a nose poke to the magazine did not result in the immediate display of a stimulus. Instead, the stimulus was delivered after a variable 5-10 s delay (the delay period), during which the animal was required to attend to the screen. If an animal prematurely touched the screen during this delay, the response was recorded as premature and the mouse was punished with a $10 \mathrm{~s}$ time-out (houselight off, magazine inactive). The time-out was followed by a 20 s ITI (houselight on, magazine inactive), after which the illumination of the magazine light signaled the onset of the next trial. The stimulus duration was initially set to $4 \mathrm{~s}$, followed by a limited holding period of $5 \mathrm{~s}$, during which the stimulus was absent but the animal was still able to respond to the location (limited holding period). Responses during stimulus presence or the limited holding period were recorded either as correct (response to the stimulus window) or incorrect (response to any other window). A correct choice was rewarded with a tone, and pellet delivery, indicated by the illumination of the magazine light. Reward collection turned the magazine light off and triggered an ITI of $20 \mathrm{~s}$. An incorrect response was punished with a $10 \mathrm{~s} \mathrm{time-out,} \mathrm{followed} \mathrm{by} \mathrm{a} 20 \mathrm{~s}$ ITI. A failure to respond to any window either during stimulus display or the limited holding period was recorded as an omission and punished with a $10 \mathrm{~s}$ time-out, followed by a $20 \mathrm{~s}$ ITI. Additional, perseverative responses to the screen after premature (during time-out), correct (before collecting the reward) and incorrect (during time-out) choices were also recorded. 


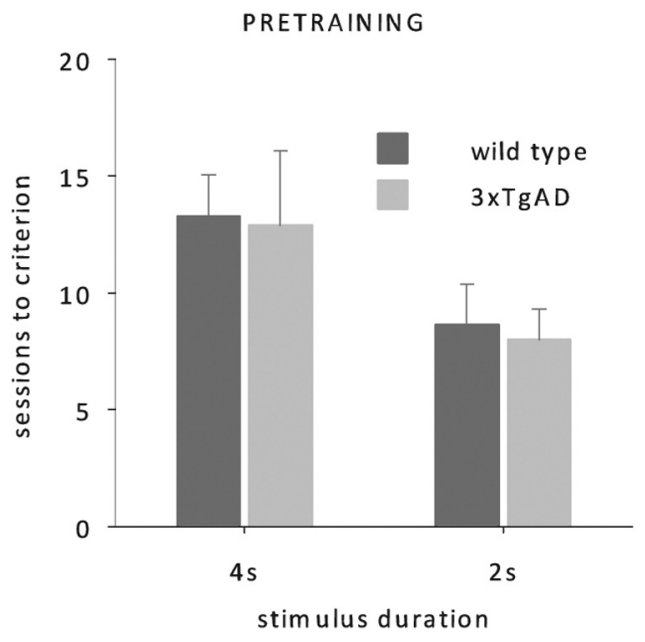

Figure 2. 5-CSRTT training data. Mean number of sessions (50 trials each) required to reach criterion at stimulus duration of 4 and 2 s for $3 \times \operatorname{TgAD}(n=8)$ and wild-type mice $(n=8)$. Mice were 36 weeks old at the onset of testing.

Once the performance of a mouse stabilized at $4 \mathrm{~s}$ stimulus duration ( $>80 \%$ accuracy, $<20 \%$ omissions for 3 consecutive days), the stimulus duration was reduced to $2 \mathrm{~s}$. After reaching criterion with the $2 \mathrm{~s}$ stimulus, animals were tested two more days. The mean measures of those $2 \mathrm{~d}$ were used to assess baseline performance.

5-CSRTT probe trials. After completing training at $2 \mathrm{~s}$ stimulus duration, animals were challenged with an increased attentional demand by reducing the stimulus duration to $1.5,1,0.8$, and $0.6 \mathrm{~s}$. To control for order effects, the sequence of stimulus durations presented to each animal in a group was randomized in a Latin square design. Each animal performed 2 consecutive days at a given stimulus duration, and was then moved back onto a $2 \mathrm{~s}$ stimulus duration for $2 \mathrm{~d}$, or until it reattained criterion ( $>80 \%$ accuracy, $<20 \%$ omissions).

Drug administration. Donepezil hydrochloride (Toronto Research Chemicals) was dissolved freshly each day in physiological saline $(0.9 \%$ sodium chloride, pH 7.0; Aquapharm; Animalcare UK). One hour before performance on the 5-CSRTT ( 0.8 and $0.6 \mathrm{~s}$ stimulus duration), mice received intraperitoneal injections $(0.1 \mathrm{ml} / 10 \mathrm{~g}$ body weight $)$ of either saline or one of 3 doses of donepezil $(0.03 \mathrm{mg} / \mathrm{kg}, 0.1 \mathrm{mg} / \mathrm{kg}, 0.3 \mathrm{mg} / \mathrm{kg})$. Doses of donepezil were chosen according to our previous validations (Bartko et al., 2010) and other published findings with transgenic mouse models (Yuede et al., 2007). The order of doses was counterbalanced in a Latin square design for each group and stimulus duration. Each dosing day was followed by three drug-free washout days where mice were tested with a stimulus duration of $2 \mathrm{~s}$.

Data analysis. Attention and response control were assessed by measuring response accuracy (correct trials divided by correct plus incorrect trials in \%), omissions (omitted trials divided by total trials in \%), premature responses (premature trials divided by total trials), perseverative responses (perseverative responses per choice), and response and magazine latencies after correct choices (in milliseconds). Means are displayed with SEM and were submitted to one-way or repeated-measures (RM) ANOVA as indicated. Simple main effects were used for post hoc analyses of within-subject effects. All statistical analyses were conducted with a significance level of $\alpha=0.05$, using SPSS Version 17.

\section{Results}

\section{Pretraining}

Wild-type and 3xTgAD mice acquired the pretraining phase of the task without any apparent differences. Sessions to criterion for neither the $4 \mathrm{~s}$ nor the subsequent $2 \mathrm{~s}$ phase were significantly different between the two groups (Fig. 2, one-way ANOVAs, no effects of genotype, all $F<1, p>0.1$ ).
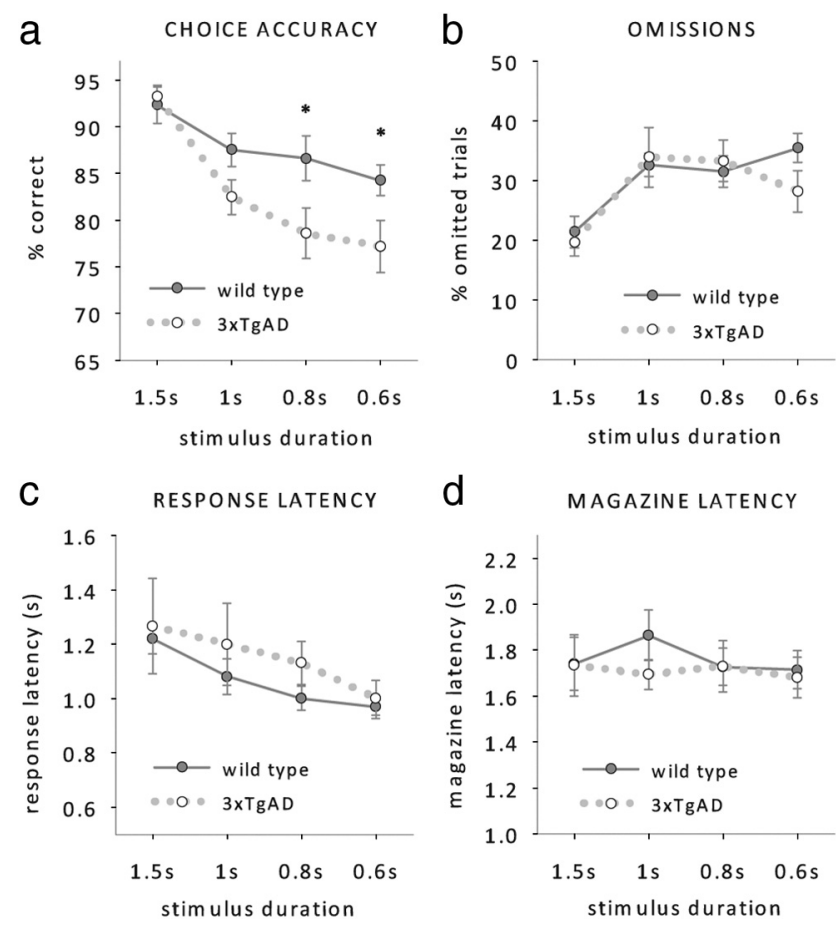

Figure 3. 5-CSRTT performance at reduced stimulus durations. $\boldsymbol{a}-\boldsymbol{d}$, Mean accuracy $(\boldsymbol{a})$ omissions $(\boldsymbol{b})$, response latencies $(\boldsymbol{c})$, and magazine latencies $(\boldsymbol{d})$ of $3 \times \operatorname{TgAD}$ and wild-type controls ( $n=8$ per genotype, age $38-40$ weeks) at stimulus durations of $1.5,1,0.8$, and $0.6 \mathrm{~s}$. ${ }^{*} p<0.05$, simple main effect of genotype.

\section{Baseline performance}

$3 x \operatorname{TgAD}$ mice showed normal performance when stimuli were presented for $2 \mathrm{~s}$, a test of relatively low attentional demand. Neither response accuracy nor omissions differed between genotypes (accuracy: wt, $96.4 \pm 0.8 ; 3 x \mathrm{TgAD}, 95.3 \pm 0.9$; omissions: wt, $15.6 \pm 2.3$; $3 x \operatorname{TgAD}, 12.8 \pm 2.9$; one-way ANOVA, no effects of genotype, all $F<1, p>0.1$ ). Furthermore, baseline performance at $2 \mathrm{~s}$ stimulus duration gave no convincing evidence of altered responding in $3 \mathrm{xTgAD}$ mice: neither premature responses nor perseverative responses-measures of impulsive and compulsive behavior-were significantly different between groups (premature responses: wt, $2.2 \pm 1.2$; 3xTgAD, $2.2 \pm 0.9$; perseverative correct: wt, $0.05 \pm 0.02 ; 3 x T g A D, 0.07 \pm 0.02$; perseverative incorrect: $w t, 1.1 \pm 0.2$; $3 \times \mathrm{TgAD}, 1.2 \pm 0.4$; perseverative premature: $w t, 1.0 \pm 0.6 ; 3 x \mathrm{TgAD}, 1.1 \pm 0.4$; one-way ANOVAs, no effects of genotype, all $F<1, p>0.1$ ). Measures of response and magazine latencies of both genotypes gave no evidence of altered motivation or motor control in 3xTgAD mice (magazine latencies: $w t, 1.2 \pm 0.1 ; 3 x T g A D, 1.3 \pm 0.2$; response latencies: wt, $1.6 \pm 0.1$; $3 \times \mathrm{TgAD}, 1.6 \pm 0.1$; one-way ANOVAs, no effect of genotype: all $F<1, p>0.1$ ).

\section{Probe trials}

After pretraining, mice were challenged with decreasing stimulus durations of $1.5 \mathrm{~s}, 1 \mathrm{~s}, 0.8 \mathrm{~s}$ and $0.6 \mathrm{~s}$. The increase of attentional demand revealed an attentional deficit in 3xTgAD mice that was most prominent at short stimulus durations and expressed by a decrease in response accuracy (Fig. 3a, RM ANOVA; main effect of genotype: $F_{(1,14)}=8.2, p<0.05$, genotype by duration interaction: $F_{(3,42)}=6.7, p<0.05$, effect of duration, $F_{(3,42)}=21.9$, $p<0.001$, no other effects or interactions, all $F<1, p>0.1$ ). Although 3xTgAD mice responded as accurately as wild-type mice at $1.5 \mathrm{~s}$ stimulus duration (simple main effect of genotype: 


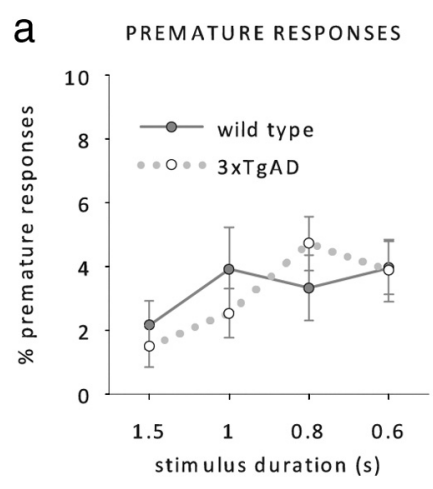

C

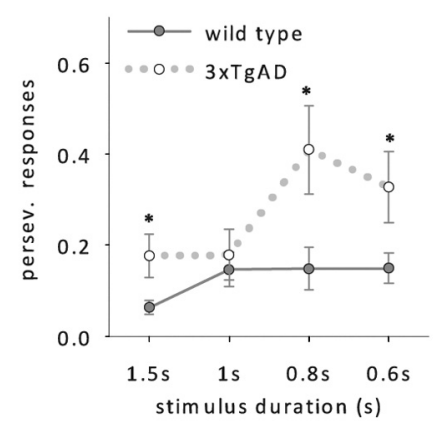

Figure 4. Response measures at reduced stimulus durations. $\boldsymbol{a}-\boldsymbol{d}$, Mean premature responses $(\boldsymbol{a})$, perseverative responses after a premature choice $(\boldsymbol{b})$, perseverative responses after a correct choice $(\boldsymbol{c})$, and perseverative responses after an incorrect choice $(\boldsymbol{d})$ of $3 \times \mathrm{TgAD}$ and wild-type controls ( $n=8$ per genotype, age $38-40$ weeks) at stimulus durations of $1.5 \mathrm{~s}, 1 \mathrm{~s}$, $0.8 \mathrm{~s}$, and $0.6 \mathrm{~s} .{ }^{*} p<0.05$, simple main effect of genotype.

$F<1, p>0.5$ ), they started to show a trend of reduced accuracy at $1 \mathrm{~s}$ stimulus duration ( $3.4, p=0.057)$ and expressed a significant accuracy deficit at $0.8 \mathrm{~s}$ (simple main effect of genotype: $\left.F_{(1,14)}=4.4, p<0.05\right)$ and $0.6 \mathrm{~s}$ (simple main effect of genotype: $F_{(1,14)}=4, p<0.05$ ).

The attentional deficit in $3 \times$ TgAD mice was restricted to a reduction in response accuracies, whereas the number of omissions made by wild-type and 3xTgAD animals remained similar (Fig. $3 b$, RM ANOVA; main effect of duration: $F_{(1,14)}=8.7, p<$ 0.001 , no further main effects or interactions, all $F<1, p>0.1$ ). No group differences were found on response latencies (Fig. 3c, RM ANOVA; main effect of duration, $\left.F_{(3,42)}=7.2, p<0.001\right)$ or magazine latencies (Fig. 3d, RM ANOVA; no main effects or interactions, all $F<1, p>0.5$ ). We also found no evidence of different premature responding between the two genotypes (Fig. $4 a$, RM ANOVA; main effect of duration, $F_{(1,14)}=3.4, p>0.05$, no other main effects or interactions, all $F<1, p<0.3$ ), which suggests that impulsivity is not altered in 3xTgAD mice.

However, 3xTgAD mice showed a higher tendency to perseverate after a correct choice despite positive reward signaling, which suggests that $3 \mathrm{xTgAD}$ mice behave more compulsively than their wild-type littermates (Fig. 4c, RM ANOVA; main effect of genotype, $F_{(1,14)}=4.2, p<0.05$, no genotype by stimulus duration interaction, $\left.F_{(1,14)}=2.4, p>0.07\right)$. In contrast, perseverative responding after incorrect and premature responses was not significantly altered in 3xTgAD mice (Fig. $4 b, d$, no effects of genotype or interactions, all $F<3.6, p>0.08$ ).

In MCI and $\mathrm{AD}$ patients, attentional impairments are most consistently observed as a reduction of vigilance (i.e., the ability to sustain attention over a long period of time) on sustained attention tasks like the Continuous Performance Task (Grady et

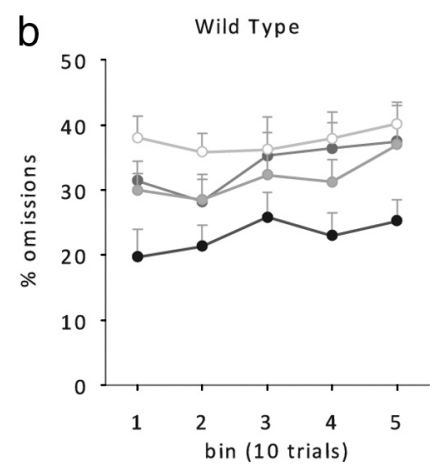

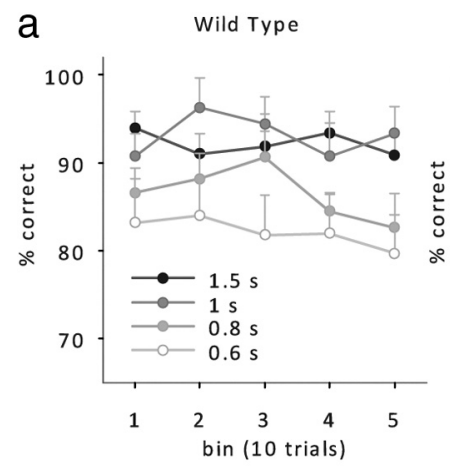
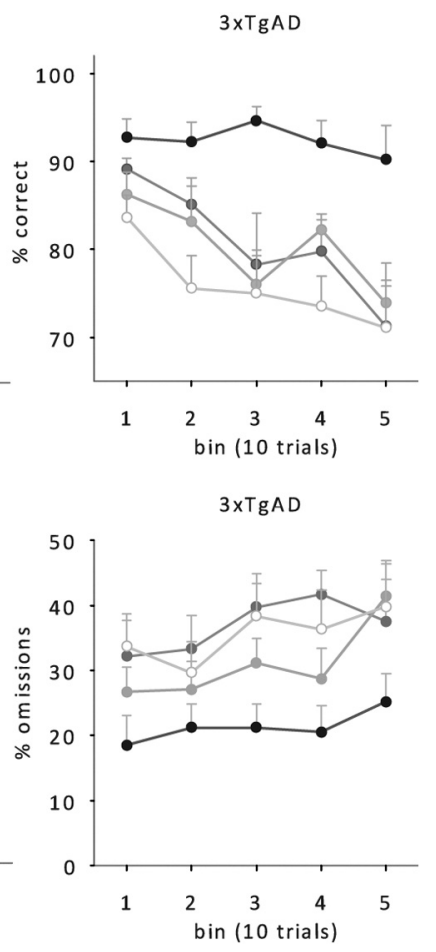

Figure 5. Vigilance test. $\boldsymbol{a}, \boldsymbol{b}$, Mean response accuracies $(\boldsymbol{a})$ and omissions $(\boldsymbol{b})$ for bins of 10 trials of wild-type and $3 x \operatorname{TgAD}$ mice ( $n=8$ per genotype, age $38-40$ weeks) at $1.5,1,0.8$, and 0.6 s stimulus durations.

al., 1988; Jones at al., 1992; Sahakian and Coull, 1993; Sahakian et al., 1993; Baddeley et al., 1999; Perry and Hodges, 1999; Berardi et al., 2005). We therefore analyzed response accuracies and omissions of wild-type and 3xTgAD mice across blocks of 10 trials to get a measure of vigilance within the daily sessions of 50 trials. The accuracy of wild-type mice, although decreasing with shorter stimulus durations, was consistent across blocks (Fig. $5 a$, left, RM ANOVA; main effect of stimulus duration: $F_{(3,21)}=3.57$, $p<0.05$, no effect of block $\left.F_{(4,28)}=1.5, p>0.1\right)$. In contrast, $3 \mathrm{xTgAD}$ mice performed constantly across a session only when the attentional demand was low, i.e., with $1.5 \mathrm{~s}$ stimulus duration (Fig. $5 a$, right). When the stimulus duration was reduced, 3xTgAD performance dropped rapidly across blocks (RM ANOVA, main effect of stimulus duration, $F_{(3,21)}=16.3, p<0.001$; main effect of block, $\left.F_{(4,28)}=8.6, p>0.001\right)$. Thus, the deficit in response accuracy we detected in the $3 \mathrm{xTgAD}$ mice at lower stimulus durations (Fig. $3 a$ ) is primarily due to reduced vigilance of these animals.

The number of omitted trials increased slightly across a session. However the increase within each session was similar at all stimulus durations and was not significantly different between genotypes (Fig. $5 b$; main effect of stimulus duration, $F_{(3,21)}=$ $21.2, p<0.001$; main of block $F_{(4,28)}=8.0, p>0.001$, no main effect of genotype or interactions, all $F<1$; $p>0.1$ ).

\section{Donepezil ameliorates response accuracy deficits in 3xTgAD mice}

Attention, and in particular choice accuracy on the 5-CSRTT, is modulated by cholinergic neurons of the basal forebrain (Muir et al., 1994; Dalley et al., 2001, 2004; McGaughy et al., 2002; Bentley et al., 2008). We therefore assessed whether the cholinesterase inhibitor donepezil (Aricept) can improve choice accuracy in $3 \mathrm{xTgAD}$ mice. Animals received either saline or donepezil at 0.03 , 

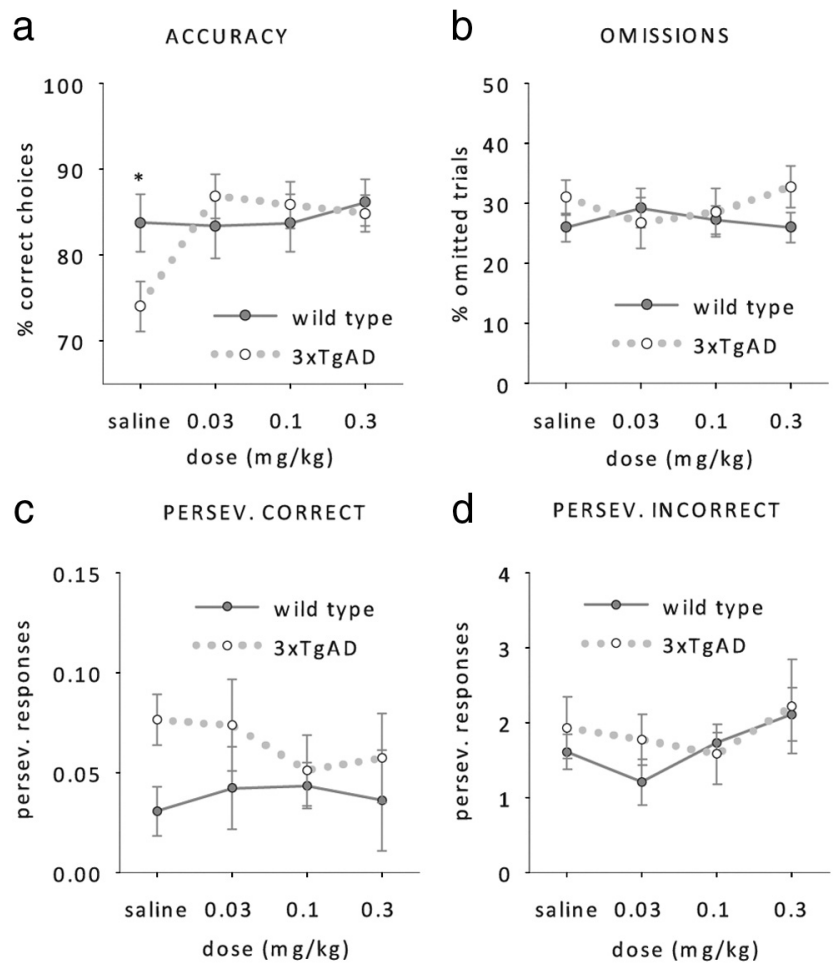

Figure 6. Effect of donepezil. $\boldsymbol{a}-\boldsymbol{d}$, Mean choice accuracy $(\boldsymbol{a})$, omissions $(\boldsymbol{b})$, perseverative responses after a correct choice $(\boldsymbol{c})$, and perseverative responses after an incorrect choice $(\boldsymbol{d})$ of wild-type and $3 x \operatorname{TgAD}$ mice ( $n=8$ per genotype, age $42-44$ weeks) $1 \mathrm{~h}$ after saline, 0.03 $\mathrm{mg} / \mathrm{kg}$ donepezil, $0.01 \mathrm{mg} / \mathrm{kg}$ donepezil, and $0.03 \mathrm{mg} / \mathrm{kg}$ donepezil injections, at a stimulus duration of $0.8 \mathrm{~s} .{ }^{*} p<0.05$, simple main effect of genotype.

0.1 or $0.3 \mathrm{mg} / \mathrm{kg} 1 \mathrm{~h}$ before performance on the 5-CSRTT with a stimulus duration of $0.8 \mathrm{~s}$. Saline-treated $3 \times$ TgAD mice still responded less accurately than wild-type mice, but all doses of donepezil abolished this deficit (Fig. 6a, RM ANOVA; donepezil by genotype interaction, $F_{(3,42)}=3.4, p<0.05$, effect of genotype with saline: $F_{(1,14)}=3.6, p<0.05$, no further effects of genotype, all $F>1, p>0.4)$. Donepezil selectively increased 3xTgAD response accuracy, without affecting wild-type performance (simple main effect of donepezil on 3xTgAD: $F_{(3,12)}=4.8, p<0.05$, simple main effect of donepezil on wt: $F<1, p>0.78)$. The acetylcholinesterase inhibitor had no effect on omissions (Fig. $6 b$ ), perseverative responses (Fig. $6 c, d$ ) or premature responses (data not shown) in either genotype (RM ANOVAs, no effects or interactions, all $F<1, p>0.3$ ).

Again, we analyzed choice accuracies and omissions of both genotypes across blocks of 10 trials within a session to get a measure of vigilance with and without donepezil. To increase statistical power, the data from the two lowest doses of donepezil were pooled and compared with saline performance (Fig. 7 ). As observed in untreated $3 \mathrm{xTgAD}$ mice, choice accuracies of saline-treated 3xTgAD mice dropped across blocks. In contrast, donepezil-treated 3xTgAD mice were able to maintain the same level of accuracy throughout the whole session just like their wild-type litter mates (Fig. 7a, RM ANOVA; donepezil by block interaction, $F_{(4,28)}=2.5, p>0.05$, no other main effects or interactions, all $F<1, p>0.2$ ). No effect of donepezil was observed on the number of omitted trials (Fig. $7 b$, RM ANOVA; no effect of donepezil or interaction involving donepezil, all $F<1, p>0.1$ ). These data suggest that donepezil enhances choice accuracy selectively in $3 \times \mathrm{TgAD}$
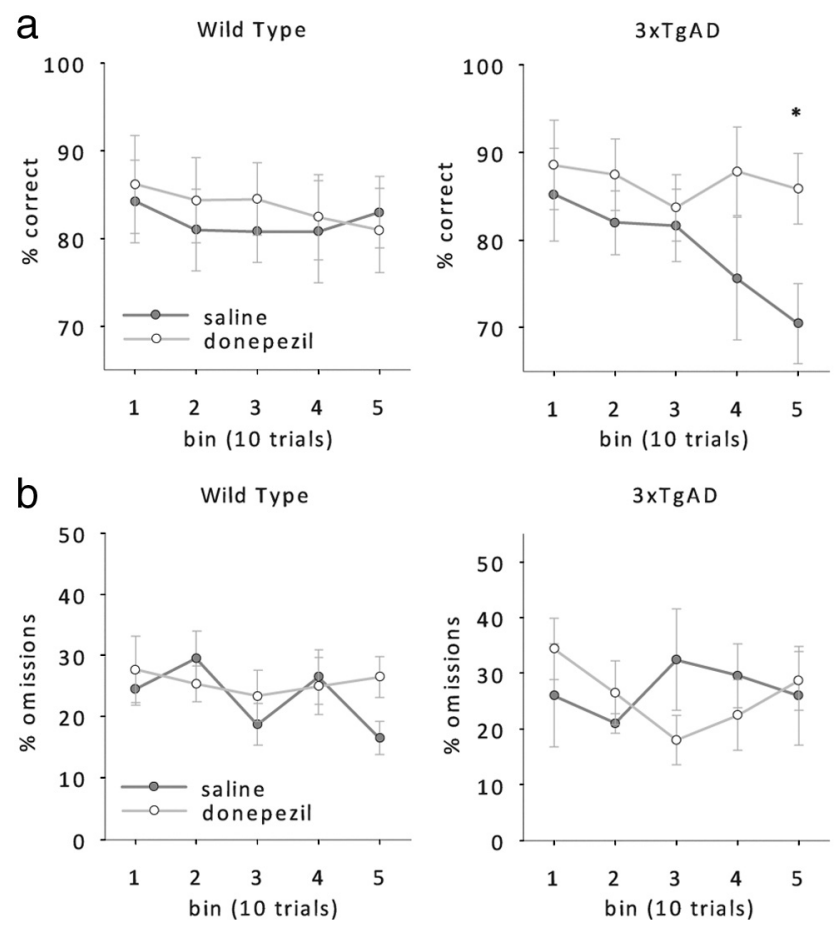

Figure 7. Effect of donepezil on vigilance. $\boldsymbol{a}, \boldsymbol{b}$, Mean response accuracies ( $\boldsymbol{a}$ ) and omissions (b) of wild-type and 3xTgAD mice ( $n=8$ per genotype, age 42-44 weeks) after saline or donepezil treatment (pooled data of $0.03 \mathrm{mg} / \mathrm{kg}$ donepezil and $0.01 \mathrm{mg} / \mathrm{kg}$ donepezil). ${ }^{*} p<$ 0.05 , simple main effect of donepezil.

mice by enhancing their vigilance, i.e., their ability to maintain a constant level of attention across time.

\section{Discussion}

\section{3xTgAD mice have attention deficits}

$3 \times T g A D$ mice with overexpression of human $A P P_{\text {swe }}$, $P S 1_{\mathrm{M} 146 \mathrm{~V}}$, and $\mathrm{tau}_{\mathrm{P} 301 \mathrm{~L}}$ genes are considered a comprehensive model of AD pathology, because they develop an age-dependent accumulation of plaques and tangles in $\mathrm{AD}$-relevant brain regions as well as impaired synaptic plasticity and loss of cholinergic receptors (Billings et al., 2005). However, 3xTgAD mice do not show any prominent neuronal loss, which is the most obvious pathological event during later stages of AD. 3xTgAD mice and most other animal models therefore probably more closely simulate the early phases of the disease asymptomatic of major cognitive decline (see Zahs and Ashe, 2010 for a recent discussion of this issue).

In addition to $\mathrm{AD}$-typical physiological and anatomical alterations, 3xTgAD mice also develop memory deficits comparable to MCI and early AD patients (Oddo et al., 2003b; Billings et al., 2005; Nelson et al., 2007). However, it has been unclear whether these mutations affect attention, which is also compromised in MCI and early AD patients (Grady et al., 1988; Sahakian and Coull, 1993; Sahakian et al., 1993; Lawrence and Sahakian, 1995; Reid et al., 1996; Perry et al., 2000; Baddeley et al., 2001; Perry and Hodges, 2003; Foldi et al., 2005b; Levinoff et al., 2005; Bentley at al., 2008). Here, we show that $3 x$ TgAD mice express a specific attentional impairment on the 5-CSRTT. Similar to vigilance deficits in human AD patients (Sahakian et al., 1989; Jones at al., 1992; Baddeley et al., 1999; Perry and Hodges, 1999; Berardi et al., 2005), 3xTgAD mice initially responded as accurately as wildtype mice, but subsequently failed to sustain their attention over the duration of the task. Although it is possible that the 
reported changes in accuracy reflect effects on basic visual sensory function, we think this is unlikely, since 3xTgAD mice responded as accurately as wild-type mice at the beginning of each session (Fig. 5).

Sustained attention deficits may also be expressed as an increase in omissions (Humby et al., 1999), which can either be interpreted as a change in sensory, motor or motivational factors, or as a gross failure to attend to the stimulus display area (in the absence of enhanced magazine latencies). However, 3xTgAD mice did not omit more trials than wild-type mice, which argues against basic sensory, motor or motivation alterations, an argument further supported by unaltered magazine latencies. On the other hand, in light of the reduction in response accuracies, it may seem surprising that $3 \mathrm{xTgAD}$ do not omit more trials than wild-type littermates. Yet, a similar pattern of impairments can be observed after inactivation of the prefrontal cortex (PFC) in rats: cholinergic denervation of this region with 192 IgG-saporin injections into the nucleus basalis of Meynert (NBM) produced dose-dependent effects on attentional accuracy and an increase in perseverative responses, without significantly affecting the number of omissions. Furthermore, accuracy changes, but not omissions or perseverative responses, correlated significantly both with cholinergic cell loss in the NBM and with reductions in ACh efflux in the prefrontal cortex (McGaughy et al., 2002; Dalley et al., 2004). Thus, the selective accuracy decrement in 3xTgAD mice may reflect a deficit of cholinergic function, whereas increases in omissions, premature and perseverative responding may be more sensitive to manipulations of other neurotransmitter systems (Robbins, 2002).

Human imaging studies also highlight the importance of the prefrontal cortex and its cholinergic afferents for detecting and reporting temporally unpredictable stimuli (Bentley et al., 2003, 2008). Hence, the attentional impairment of $3 x \operatorname{tgAD}$ mice may be the result of pathological changes in the prefrontal cortex or the cholinergic neurons of the basal forebrain. Indeed, the prefrontal cortex of $3 \mathrm{xTgAD}$ is among the first brain regions to be affected by $\beta$-amyloid pathology: profound rises of intracellular $\beta$-amyloid occur around 6 months of age (Hirata-Fukae et al., 2008). Another potential cause of the observed attentional deficits in 3xTgAD mice is toxicity triggered by aberrantly phosphorylated tau. Human patients with FTDP, which exhibit extensive tau pathology but no $\mathrm{A} \beta$ pathology, manifest attentional deficits (Perry and Hodges, 2000; Piquard et al., 2009). In our 3xTgAD mice, tau pathology appears around 8-12 months of age first in the hippocampus and somewhat later in the PFC (Nelson et al., 2007; M. P. Mattson, unpublished data) suggesting a potential contribution of tau to the attention deficits in these mice. However, transgenic mice expressing the human FTDP-17 tauV337M mutation show normal response accuracies on the classic 5-CSRTT (Lambourne et al., 2007). Thus, we speculate that the attentional impairments in our $3 \times \mathrm{TgAD}$ mice are related to $\mathrm{A} \beta$ accumulation and/or cholinergic receptor depletion, although we cannot rule out a role for tau pathology in cholinergic neurons.

Around 8-12 months of age, $\beta$-amyloid accumulation and hyperphosphorylated tau aggregates also begin to affect the hippocampus of 3xTgAD mice (Nelson et al., 2007), coinciding with learning deficits, impaired cholinergic modulation of hippocampal synaptic plasticity (Wang et al., 2009) and a selective loss of cholinergic, nicotinic $\alpha 7$ receptors (Oddo et al., 2005) that also occurs in $\mathrm{AD}$ patients (Whitehouse and $\mathrm{Au}, 1986$ ). Thus, because the 5-CSRTT has a clear spatial component, it is also possible that hippocampal rather than prefrontal dysfunction predominantly contributes to the accuracy deficit in 3xTgAD mice. However, we think this is unlikely, since hippocampal manipulations have previously not affected the performance of trained animals on 5-CSRTT (Kirkby and Higgins, 1998).

\section{Donepezil rescues the attention deficit of 3xTgAD mice}

Consistent with compromised prefrontal cortex function, we showed that the attentional deficit of 3xTgAD mice was ameliorated by the anticholinesterase donepezil, which enhances the availability of ACh at the synapse. Donepezil had no effect on wild-type performance, which argues for a cholinergic deficit in $3 x$ TgAD mice. Although anticholinesterases enhance attention in rats with AMPA-lesioned NBM (Muir et al., 1994), ACh levels increase in the PFC during 5-CSRTT performance (Dalley et al., 2001) and intra-PFC infusion of scopolamine is very disruptive to 5-CSRTT accuracy (Robbins et al., 1998), it remains to be confirmed whether the attention-enhancing effect of donepezil in $3 \times$ TGAD mice is indeed due to enhancing cholinergic transmission in the PFC.

Considerable evidence suggests that cholinergic depletion might also be an important factor in AD: the degree of cognitive impairments in AD patients is positively correlated with a decrease in choline acetyltransferase activity and neuronal activity in cholinergic brain regions (Perry et al., 1978; Francis et al., 1985; Tiraboschi et al., 2000; Bentley et al., 2008). Furthermore, similar to our findings in the $3 \times \mathrm{TgAD}$ mouse, anticholinesterase treatment improved attention in MCI and AD patients (Sahakian and Coull, 1993; Sahakian et al., 1993; Lawrence and Sahakian, 1995; Blin et al., 1998; Rockwood et al., 2004; Foldi et al., 2005a; Bentley et al., 2008), interestingly without significantly affecting learning abilities (Sahakian and Coull, 1993; Sahakian et al., 1993). However, it remains to be investigated whether attentional impairments in 3xTGAD mice and AD patients are indeed comparable and based on the same pathological processes.

\section{3xTgAD mice show signs of compulsive behavior}

In addition to a choice accuracy deficit, $3 x \mathrm{TgAD}$ mice made more perseverative correct responses, i.e., repeated responses to the touchscreen during the $5 \mathrm{~s}$ response window despite signaled food presentation. Perseverative behavior is thought to represent an inhibitory response control deficit that can be described as "compulsive" behavior (Robbins, 2002). Perseverative responding can be distinguished from another form of inhibitory control deficit more akin to impulsivity (acting without foresight): premature responding while the mouse is anticipating the occurrence of the visual target (Chudasama and Robbins, 2004). The latter process was unaltered in $3 \mathrm{xTgAD}$ mice. The dissociation of differently affected inhibitory control mechanisms in 3xTgAD mice may relate to the selective involvement of distinct subareas within the PFC: lesions made to the rat medial prelimbic cortex, as well as rat orbitofrontal lesions, produce selective increases in perseverative responses (Chudasama and Muir, 2001; Passetti et al., 2002); lesions centered on the ventral infralimbic cortex can cause selective increases in premature responses only (Chudasama et al., 2003).

Little work has been done studying such behaviors in $\mathrm{AD}$ patients; however it is interesting to note that in one study, a subset of $\mathrm{AD}$ patients did indeed show evidence of compulsive behavior, although this phenotype occurred more in patients with frontotemporal dementia (Mendez et al., 1997). Furthermore, perseveration in a more general sense, i.e., any continuation or recurrence of an earlier verbal or nonverbal response without an appropriate intervening stimulus, is a common fea- 
ture of AD (Lamar et al., 1997; Traykov et al., 2005; Pekkala et al., 2008).

In summary, our results demonstrate that mice with APPswe, PS1M146V, and tauP301L mutations exhibit not only memory deficits, but also significant impairments in attention that may be caused by pathological manifestations in the prefrontal cortex or its afferents. Because attentional deficits and prefrontal pathology per se are likely to interfere with memory encoding, care is required when interpreting memory task performance of 3xTgAD and possibly other animal models of the disease. Studying attention in such models may prove to be a particularly suitable and relatively unconfounded approach to investigating correlations of $\mathrm{AD}$-like cellular pathological changes with the development of cognitive deficits and their amelioration with pharmacological and other therapeutic approaches.

\section{References}

Artero S, Ritchie K (2003) The detection of mild cognitive impairment in the general practice setting. Aging Ment Health 7:251-258.

Baddeley A, Cocchini G, Della Sala S, Logie RH, Spinnler H (1999) Working memory and vigilance: evidence from normal aging and Alzheimer's disease. Brain Cogn 41:87-108.

Baddeley AD, Baddeley HA, Bucks RS, Wilcock GK (2001) Attentional control in Alzheimer's disease. Brain 124:1492-1508.

Balducci C, Nurra M, Pietropoli A, Samanin R, Carli M (2003) Reversal of visual attention dysfunction after AMPA lesions of the nucleus basalis magnocellularis (NBM) by the cholinesterase inhibitor donepezil and by a 5-HT1A receptor antagonist WAY 100635. Psychopharmacology (Berl) 167:28-36.

Bartko SJ, Vendrell I, Saksida LM, Bussey TJ (2010) A computer-automated touchscreen paired-associates learning (PAL) task for mice: impairments following administration of scopolamine or dicyclomine and improvements following donepezil. Psychopharmacology (Berl). Advance online publication. Retrieved November 18, 2010. doi:10.1007/s00213-010-2050-1.

Bentley P, Vuilleumier P, Thiel CM, Driver J, Dolan RJ (2003) Cholinergic enhancement modulates neural correlates of selective attention and emotional processing. Neuroimage 20:58-70.

Bentley P, Driver J, Dolan RJ (2008) Cholinesterase inhibition modulates visual and attentional brain responses in Alzheimer's disease and health. Brain 131:409-424.

Berardi AM, Parasuraman R, Haxby JV (2005) Sustained attention in mild Alzheimer's disease. Dev Neuropsychol 28:507-537.

Billings LM, Oddo S, Green KN, McGaugh JL, LaFerla FM (2005) Intraneuronal Abeta causes the onset of early Alzheimer's disease-related cognitive deficits in transgenic mice. Neuron 45:675-688.

Blin J, Ivanoiu A, De Volder A, Michel C, Bol A, Verellen C, Seron X, Duprez T, Laterre EC (1998) Physostigmine results in an increased decrement in brain glucose consumption in Alzheimer's disease. Psychopharmacology (Berl) 136:256-263.

Blondel A, Sanger DJ, Moser PC (2000) Characterisation of the effects of nicotine in the five-choice serial reaction time task in rats: antagonist studies. Psychopharmacology (Berl) 149:293-305.

Carli M, Robbins TW, Evenden JL, Everitt BJ (1983) Effects of lesions to ascending noradrenergic neurones on performance of a 5-choice serial reaction task in rats; implications for theories of dorsal noradrenergic bundle function based on selective attention and arousal. Behav Brain Res 9:361-380.

Chudasama Y, Muir JL (2001) Visual attention in the rat: a role for the prelimbic cortex and thalamic nuclei? Behav Neurosci 115:417-428.

Chudasama Y, Robbins TW (2004) Psychopharmacological approaches to modulating attention in the five-choice serial reaction time task: implications for schizophrenia. Psychopharmacology (Berl) 174:86-98.

Chudasama Y, Passetti F, Rhodes SE, Lopian D, Desai A, Robbins TW (2003) Dissociable aspects of performance on the 5-choice serial reaction time task following lesions of the dorsal anterior cingulate, infralimbic and orbitofrontal cortex in the rat: differential effects on selectivity, impulsivity and compulsivity. Behav Brain Res 146:105-119.

Dalley JW, McGaughy J, O'Connell MT, Cardinal RN, Levita L, Robbins TW (2001) Distinct changes in cortical acetylcholine and noradrenaline ef- flux during contingent and noncontingent performance of a visual attentional task. J Neurosci 21:4908-4914.

Dalley JW, Theobald DE, Bouger P, Chudasama Y, Cardinal RN, Robbins TW (2004) Cortical cholinergic function and deficits in visual attentional performance in rats following $192 \mathrm{IgG}$-saporin-induced lesions of the medial prefrontal cortex. Cereb Cortex 14:922-932.

Davies P, Maloney AJ (1976) Selective loss of central cholinergic neurons in Alzheimer's disease. Lancet 2:1403.

de Bruin NM, Fransen F, Duytschaever H, Grantham C, Megens AA (2006) Attentional performance of $(\mathrm{C} 57 \mathrm{BL} / 6 \mathrm{~J} \times 129 \mathrm{~Sv}) \mathrm{F} 2$ mice in the fivechoice serial reaction time task. Physiol Behav 89:692-703.

Dermaut B, Kumar-Singh S, Rademakers R, Theuns J, Cruts M, Van Broeckhoven C (2005) Tau is central in the genetic Alzheimer-frontotemporal dementia spectrum. Trends Genet 21:664-672.

Foldi NS, White RE, Schaefer LA (2005a) Detecting effects of donepezil on visual selective attention using signal detection parameters in Alzheimer's disease. Int J Geriatr Psychiatry 20:485-488.

Foldi NS, Schaefer LA, White RE, Johnson R Jr, Berger JT, Carney MT, Macina LO (2005b) Effects of graded levels of physical similarity and density on visual selective attention in patients with Alzheimer's disease. Neuropsychology 19:5-17.

Francis PT, Palmer AM, Sims NR, Bowen DM, Davison AN, Esiri MM, Neary D, Snowden JS, Wilcock GK (1985) Neurochemical studies of early-onset Alzheimer's disease. Possible influence on treatment. N Engl J Med 313: $7-11$.

Götz J, Ittner LM (2008) Animal models of Alzheimer's disease and frontotemporal dementia. Nat Rev Neurosci 9:532-544.

Grady CL, Haxby JV, Horwitz B, Sundaram M, Berg G, Schapiro M, Friedland RP, Rapoport SI (1988) Longitudinal study of the early neuropsychological and cerebral metabolic changes in dementia of the Alzheimer type. J Clin Exp Neuropsychol 10:576-596.

Haass C (1997) Presenilins: genes for life and death. Neuron 18:687-690.

Hirata-Fukae C, Li HF, Hoe HS, Gray AJ, Minami SS, Hamada K, Niikura T, Hua F, Tsukagoshi-Nagai H, Horikoshi-Sakuraba Y, Mughal M, Rebeck GW, LaFerla FM, Mattson MP, Iwata N, Saido TC, Klein WL, Duff KE, Aisen PS, Matsuoka Y (2008) Females exhibit more extensive amyloid, but not tau, pathology in an Alzheimer transgenic model. Brain Res 1216:92-103.

Huff FJ, Growdon JH, Corkin S, Rosen TJ (1987a) Age at onset and rate of progression of Alzheimer's disease. J Am Geriatr Soc 35:27-30.

Huff FJ, Becker JT, Belle SH, Nebes RD, Holland AL, Boller F (1987b) Cognitive deficits and clinical diagnosis of Alzheimer's disease. Neurology 37:1119-1124.

Humby T, Laird FM, Davies W, Wilkinson LS (1999) Visuospatial attentional functioning in mice: interactions between cholinergic manipulations and genotype. Eur J Neurosci 11:2813-2823.

Jones DN, Higgins GA (1995) Effect of scopolamine on visual attention in rats. Psychopharmacology (Berl) 120:142-149.

Jones GM, Sahakian BJ, Levy R, Warburton DM, Gray JA (1992) Effects of acute subcutaneous nicotine on attention, information processing and short-term memory in Alzheimer's disease. Psychopharmacology (Berl) 108:485-494.

Kirkby DL, Higgins GA (1998) Characterization of perforant path lesions in rodent models of memory and attention. Eur J Neurosci 10:823-838.

Lamar M, Podell K, Carew TG, Cloud BS, Resh R, Kennedy C, Goldberg E, Kaplan E, Libon DJ (1997) Perseverative behavior in Alzheimer's disease and subcortical ischemic vascular dementia. Neuropsychology 11:523-534.

Lambourne SL, Humby T, Isles AR, Emson PC, Spillantini MG, Wilkinson LS (2007) Impairments in impulse control in mice transgenic for the human FTDP-17 tauV337M mutation are exacerbated by age. Hum Mol Genet $16: 1708-1719$.

Lawrence AD, Sahakian BJ (1995) Alzheimer disease, attention, and the cholinergic system. Alzheimer Dis Assoc Disord 9 [Suppl 2]:43-49.

Levinoff EJ, Saumier D, Chertkow H (2005) Focused attention deficits in patients with Alzheimer's disease and mild cognitive impairment. Brain Cogn 57:127-130.

McGaughy J, Dalley JW, Morrison CH, Everitt BJ, Robbins TW (2002) Selective behavioral and neurochemical effects of cholinergic lesions produced by intrabasalis infusions of 192 IgG-saporin on attentional performance in a five-choice serial reaction time task. J Neurosci 22:1905-1913. 
Mendez MF, Cherrier MM, Perryman KM (1997) Differences between Alzheimer's disease and vascular dementia on information processing measures. Brain Cogn 34:301-310.

Mirza NR, Stolerman IP (2000) The role of nicotinic and muscarinic acetylcholine receptors in attention. Psychopharmacology (Berl) 148:243-250.

Muir JL, Dunnett SB, Robbins TW, Everitt BJ (1992) Attentional functions of the forebrain cholinergic systems: effects of intraventricular hemicholinium, physostigmine, basal forebrain lesions and intracortical grafts on a multiple-choice serial reaction time task. Exp Brain Res 89:611-622.

Muir JL, Everitt BJ, Robbins TW (1994) AMPA-induced excitotoxic lesions of the basal forebrain: a significant role for the cortical cholinergic system in attentional function. J Neurosci 14:2313-2326.

Nelson RL, Guo Z, Halagappa VM, Pearson M, Gray AJ, Matsuoka Y, Brown M, Martin B, Iyun T, Maudsley S, Clark RF, Mattson MP (2007) Prophylactic treatment with paroxetine ameliorates behavioral deficits and retards the development of amyloid and tau pathologies in 3xTgAD mice. Exp Neurol 205:166-176.

Oddo S, Caccamo A, Shepherd JD, Murphy MP, Golde TE, Kayed R, Metherate R, Mattson MP, Akbari Y, LaFerla FM (2003a) Triple-transgenic model of Alzheimer's disease with plaques and tangles: intracellular Abeta and synaptic dysfunction. Neuron 39:409-421.

Oddo S, Caccamo A, Kitazawa M, Tseng BP, LaFerla FM (2003b) Amyloid deposition precedes tangle formation in a triple transgenic model of Alzheimer's disease. Neurobiol Aging 24:1063-1070.

Oddo S, Caccamo A, Green KN, Liang K, Tran L, Chen Y, Leslie FM, LaFerla FM (2005) Chronic nicotine administration exacerbates tau pathology in a transgenic model of Alzheimer's disease. Proc Natl Acad Sci U S A 102:3046-3051.

Passetti F, Chudasama Y, Robbins TW (2002) The frontal cortex of the rat and visual attentional performance: dissociable functions of distinct medial prefrontal subregions. Cereb Cortex 12:1254-1268.

Patel S, Stolerman IP, Asherson P, Sluyter F (2006) Attentional performance of $\mathrm{C} 57 \mathrm{BL} / 6$ and $\mathrm{DBA} / 2$ mice in the 5-choice serial reaction time task. Behav Brain Res 170:197-203.

Pattij T, Janssen MC, Loos M, Smit AB, Schoffelmeer AN, van Gaalen MM (2007) Strain specificity and cholinergic modulation of visuospatial attention in three inbred mouse strains. Genes Brain Behav 6:579-587.

Pekkala S, Albert ML, Spiro A 3rd, Erkinjuntti T (2008) Perseveration in Alzheimer's disease. Dement Geriatr Cogn Disord 25:109-114.

Perry EK, Perry RH, Blessed G, Tomlinson BE (1978) Changes in brain cholineterases in senile dementia of Alzheimer type. Neuropathol Appl Neurobiol 4:273-277.

Perry RJ, Hodges JR (1999) Attention and executive deficits in Alzheimer's disease. A critical review. Brain 122:383-404.

Perry RJ, Hodges JR (2000) Differentiating frontal and temporal variant frontotemporal dementia from Alzheimer's disease. Neurology 54:2277-2284.

Perry RJ, Hodges JR (2003) Dissociation between top-down attentional control and the time course of visual attention as measured by attentional dwell time in patients with mild cognitive impairment. Eur J Neurosci $18: 221-226$

Perry RJ, Watson P, Hodges JR (2000) The nature and staging of attention dysfunction in early (minimal and mild) Alzheimer's disease: relationship to episodic and semantic memory impairment. Neuropsychologia 38:252-271.
Piquard A, Lacomblez L, Derouesné C, Siéroff E (2009) Problems inhibiting attentional capture by irrelevant stimuli in patients with frontotemporal dementia. Brain Cogn 70:62-66.

Reid W, Broe G, Creasey H, Grayson D, McCusker E, Bennett H, Longley W, Sulway MR (1996) Age at onset and pattern of neuropsychological impairment in mild early-stage Alzheimer disease. A study of a communitybased population. Arch Neurol 53:1056-1061.

Robbins TW (2002) The 5-choice serial reaction time task: behavioural pharmacology and functional neurochemistry. Psychopharmacology (Berl) 163:362-380.

Robbins TW, Granon S, Muir JL, Durantou F, Harrison A, Everitt BJ (1998) Neural systems underlying arousal and attention. Implications for drug abuse. Ann N Y Acad Sci 846:222-237.

Rockwood K, Black SE, Robillard A, Lussier I (2004) Potential treatment effects of donepezil not detected in Alzheimer's disease clinical trials: a physician survey. Int J Geriatr Psychiatry 19:954-960.

Sahakian B, Jones G, Levy R, Gray J, Warburton D (1989) The effects of nicotine on attention, information processing, and short-term memory in patients with dementia of the Alzheimer type. Br J Psychiatry 154:797-800.

Sahakian BJ, Coull JT (1993) Tetrahydroaminoacridine (THA) in Alzheimer's disease: an assessment of attentional and mnemonic function using CANTAB. Acta Neurol Scand [Suppl 149]:29-35.

Sahakian BJ, Owen AM, Morant NJ, Eagger SA, Boddington S, Crayton L, Crockford HA, Crooks M, Hill K, Levy R (1993) Further analysis of the cognitive effects of tetrahydroaminoacridine (THA) in Alzheimer's disease: assessment of attentional and mnemonic function using CANTAB. Psychopharmacology (Berl) 110:395-401.

Selkoe DJ (1998) The cell biology of beta-amyloid precursor protein and presenilin in Alzheimer's disease. Trends Cell Biol 8:447-453.

Tiraboschi P, Hansen LA, Alford M, Masliah E, Thal LJ, Corey-Bloom J (2000) The decline in synapses and cholinergic activity is asynchronous in Alzheimer's disease. Neurology 55:1278-1283.

Traykov L, Baudic S, Raoux N, Latour F, Rieu D, Smagghe A, Rigaud AS (2005) Patterns of memory impairment and perseverative behavior discriminate early Alzheimer's disease from subcortical vascular dementia. J Neurol Sci 229-230:75-79.

Wang Y, Greig NH, Yu QS, Mattson MP (2009) Presenilin-1 mutation impairs cholinergic modulation of synaptic plasticity and suppresses NMDA currents in hippocampus slices. Neurobiol Aging 30:1061-1068.

Welsh KA, Butters N, Hughes JP, Mohs RC, Heyman A (1992) Detection and staging of dementia in Alzheimer's disease. Use of the neuropsychological measures developed for the Consortium to Establish a Registry for Alzheimer's disease. Arch Neurol 49:448-452.

Whitehouse PJ, Au KS (1986) Cholinergic receptors in aging and Alzheimer's disease. Prog Neuropsychopharmacol Biol Psychiatry 10:665-676.

Whitehouse PJ, Price DL, Struble RG, Clark AW, Coyle JT, Delon MR (1982) Alzheimer's disease and senile dementia: loss of neurons in the basal forebrain. Science 215:1237-1239.

Yuede CM, Dong H, Csernansky JG (2007) Anti-dementia drugs and hippocampal-dependent memory in rodents. Behav Pharmacol 18:347-363.

Zahs KR, Ashe KH (2010) 'Too much good news'-are Alzheimer mouse models trying to tell us how to prevent, not cure, Alzheimer's disease? Trends Neurosci 33:381-389. 